\title{
A Teoria dos Campos Conceituais num Processo de Formação Continuada de Professores
}

\author{
The Theory of Conceptual Fields in a Continuous Teacher Education \\ Process
}

\author{
Eurivalda Santana* \\ Alex Andrade Alves ${ }^{* *}$ \\ Célia Barros Nunes ${ }^{* *}$
}

\begin{abstract}
Resumo
A Teoria dos Campos Conceituais visa fornecer quadros e alguns princípios para o estudo do desenvolvimento e da aprendizagem de competências complexas dos estudantes. Compreendendo a aprendizagem como um processo que pode ser desencadeado pelas ações efetivadas no ensino, utilizamos essa teoria no desenvolvimento das ações de pesquisa embrenhadas em processos e práticas de ensino. Assim, este artigo objetiva analisar as reflexões dos professores a respeito da aplicação da Teoria dos Campos Conceituais durante um processo de formação continuada que abordou o trabalho com conceitos das Estruturas Aditivas nos anos iniciais. Trata-se de um recorte de uma pesquisa mais ampla, que tinha como objetivo principal desenvolver uma formação colaborativa entre professores dos anos iniciais e pesquisadores. Para alcançar o objetivo proposto, foi analisado o relatório final, respondido por quatro das professoras participantes do processo formativo. A análise das reflexões feitas pelas professoras, no relatório final, revela que, para elas, a aplicação dessa teoria durante o processo formativo proporcionou reflexões a respeito da forma de desenvolver o processo de ensino, além de dar suporte para a construção de atividades que dão sentido à operação matemática, possibilitando compreender as relações envolvidas nos conceitos.
\end{abstract}

Palavras-chave: Teoria dos Campos Conceituais. Formação de Professores. Prática Colaborativa.

\begin{abstract}
The Theory of Conceptual Fields aims to provide frame and some principles for the study of development and learning of students' complex skills. Comprehending the learning as a process levered by actions accomplished

\footnotetext{
* Doutora em Educação Matemática pela Pontifícia Universidade Católica de São Paulo (PUC/SP). Líder do Grupo de Pesquisa em Educação Matemática, Estatística e em Ciências (GPEMEC). Professora do Departamento de Ciências Exatas e Tecnológicas e do Programa de Pós-graduação em Educação Matemática da Universidade Estadual de Santa Cruz (UESC), Ilhéus, Bahia, Brasil. Endereço para correspondência: Rua Pernambuco, 153, Apto. 102, Jardim Vitória, CEP 45605 510, Itabuna, Bahia, Brasil. E-mail: eurivalda@uesc.br ** Doutor em Ciências da Educação pela Pontifícia Universidade Católica do Rio de Janeiro (PUC/RJ). PósDoutorando em Educação Matemática na Universidade Estadual de Santa Cruz (UESC). Bolsista CAPES/PNPD. Professor do Instituto Federal da Bahia (IFBA), Eunapólis, Bahia, Brasil. Endereço para correspondência: Rua Izolda Guimarães, 91, Apto 504, Zildolândia, CEP 45600 720, Itabuna, Bahia, Brasil. E-mail: alex.andrade.alves@gmail.com.

**** Doutora em Educação Matemática pela Universidade Estadual Paulista (UNESP Rio Claro). Líder do Grupo de Pesquisa Desenvolvimento Social. Membro do Grupo de Pesquisa Política, Gestão, Memória e Pesquisa em Educação (POGEDUC). Professora do Departamento de Educação (DEDC X), Universidade do Estado da Bahia (UNEB),Teixeira de Freitas, Bahia, Brasil. Endereço para correspondência: Av. Carter, 190, Jardim Caraípe, CEP 45998 024, Teixeira de Freitas, Bahia, Brasil. E-mail: celiabns@gmail.com
} 
in teaching, we use this theory in the development of research activities inserted in processes and practices of teaching. Thus, this article aims to analyze the teacher's reflections regarding the application of the Theory of Conceptual Fields during a process of continuous learning that focused on the work with concepts of Additive Structures in the early years. It is a cutout of a bigger research that had as main objective to develop a collaborative teacher education between early years teachers and researchers in a collaborative perspective. To realize the proposed objective, the final report was analyzed and answered by four of the participating teachers in the education process. The analysis of the reflections made by the teachers in the final report shows that, for them, the application of this theory during the education process provided reflections on the way to develop the teaching process, as well as, to give support for the construction activities that offer meaning to mathematical operation, consenting to understanding the relationships involved in these concepts.

Keywords: Theory of Conceptual Fields. Teacher education. Collaborative practice.

\section{Introdução}

O presente artigo pretende analisar as reflexões de professores a respeito da aplicação da Teoria dos Campos Conceituais, durante um processo de formação continuada, que abordou o trabalho com conceitos das Estruturas Aditivas nos anos iniciais. O processo formativo se deu em um período de oito meses, culminando com um relatório final com as professoras do Núcleo de Ilhéus $^{1}$ envolvidas. Em busca de atender ao objetivo proposto, inicialmente apresentamos, de modo sucinto, alguns fundamentos teóricos que subsidiam a compreensão das reflexões e avaliações realizadas no decorrer do texto, a saber: a Teoria do Campo Conceitual de Vergnaud, especificamente o Campo Aditivo, a formação continuada de professores e desenvolvimento profissional com base em práticas colaborativas. Dando prosseguimento, apresenta-se, sumariamente, a metodologia utilizada na pesquisa e, por fim, o trabalho colaborativo na formação continuada das professoras mediante as Estruturas Aditivas.

Antes de discorrer a respeito de pontos específicos da Teoria dos Campos Conceituais (TCC), acreditamos ser pertinente elencarmos visões gerais dessa teoria.

Trata-se de uma teoria cognitivista, que busca analisar o desenvolvimento e a aprendizagem de competências complexas dos estudantes. Para isso, subsidia o professor de modo que ele possa compreender os processos e as práticas de ensino que possibilitem o desencadeamento dos processos de aprendizagem.

A Teoria dos Campos Conceituais foi proposta pelo pesquisador francês Gérard Vergnaud, com gênese na Teoria Piagetiana, e algumas nuances observadas por Vergnaud (1996), como, por exemplo: Piaget reduz seu estudo às estruturas lógicas gerais,

\footnotetext{
${ }^{1}$ A pesquisa, aqui apresentada, foi financiada pela Fundação de Amparo à Pesquisa do Estado da Bahia (FAPESB).
} 
independentemente do conteúdo do conhecimento, o qual chamou de complexidade lógica geral. Além disso, ele não trabalhou em contextos escolares, centro de interesse de Vergnaud. Assim, na TCC, são retomados princípios de Piaget, porém é adotado como referência o conteúdo do conhecimento e a análise conceitual do domínio desse conhecimento. $\mathrm{O}$ autor entende como conhecimento "tanto o saber fazer como os saberes expressos" (VERGNAUD, 1996, p. 155). No saber fazer estão envolvidas as competências e as habilidades e, nestas, podem ser observados e analisados os saberes expressos pelo estudante, quando defrontado com as situações e, a partir daí, pode-se analisar a sua aprendizagem.

Segundo o autor, quando confrontamos os estudantes com novas situações, eles buscam utilizar os conhecimentos adquiridos em suas experiências passadas, quando em situações mais simples e mais familiares, e tentam adaptá-las a essas novas (VERGNAUD, 1988, p. 141). Nesse mesmo caminhar, buscamos compreender os conhecimentos dos professores, ao se depararem com circunstâncias que os instigam a refletir sobre a sua prática de ensino (o saber fazer) em relação a determinados conceitos matemáticos (os saberes envolvidos). É nesse momento que encontramos elementos para entender os seus conhecimentos.

Nessa visão, o autor concebe o conhecimento em Campos Conceituais, em que alguns podem ser importantes para a compreensão de outros. Dessa forma, Vergnaud (1996) considera útil falar em distintos Campos Conceituais, se eles puderem ser consistentemente descritos. Ele crê que é praticamente impossível estudar as coisas separadamente e, por isso mesmo, é preciso fazer recortes. Nesse sentido, os Campos Conceituais são unidades de estudo frutíferas, capazes de dar sentido aos problemas e às observações feitas em relação à conceitualização.

Para Vergnaud, um campo conceitual significa:

[...] um conjunto informal e heterogêneo de problemas, situações, conceitos, relações, conteúdos e operações de pensamento, conectados uns aos outros e, provavelmente, interligados durante o processo de aquisição (VERGNAUD, 1982, p. 40, tradução nossa).

Observa-se que, para o autor, as ligações do conceito com seus elementos constituem o significado fundamental de um Campo Conceitual. Acreditamos que, no processo de ensino, o trabalho com o conceito precisa ser estruturado de forma que a prática de ensino contemple a variedade de situações que o envolvem.

Nessa perspectiva, levantamos a seguinte questão de pesquisa: quais as reflexões dos professores a respeito da aplicação da Teoria dos Campos Conceituais durante um processo de 
formação continuada que abordou o trabalho com conceitos das Estruturas Aditivas nos anos iniciais?

Subsidiando essa questão de pesquisa, temos como objetivo principal analisar as reflexões dos professores a respeito da aplicação da Teoria dos Campos Conceituais, durante um processo de formação continuada, que abordou o trabalho com conceitos das Estruturas Aditivas nos anos iniciais.

\section{Situações: porta de entrada do Campo Conceitual}

Diante da definição de um campo conceitual, trazemos, aqui, o conceito de situação. Segundo Vergnaud (1996, p. 167), o conceito de situação não é o de situação didática, mas, sim, o de tarefa, sendo que "qualquer situação complexa pode ser analisada como uma combinação de tarefas", para as quais é importante conhecer suas naturezas e suas dificuldades próprias. Para o autor, a complexidade está atrelada aos próprios conceitos matemáticos envolvidos numa situação, porém, admite que outros fatores, como a linguística e a forma do enunciado de uma situação, são pertinentes para a complexidade, contudo, considera que o papel desses fatores está subordinado ao próprio conceito matemático.

Assim, é preciso oportunizar o contato do aprendiz com diversas situações, de modo a contemplar maiores condições de ampliação e desenvolvimento cognitivo. Os processos cognitivos e as respostas dadas pelo sujeito são funções das situações com as quais é confrontado. Vergnaud (1990) chama a atenção para duas ideias que são consideradas principais para as situações: a de variedade e a de história.

Essas ideias significam que, em cada Campo Conceitual, existe uma grande variedade de situações e os conhecimentos dos estudantes são moldados pelas situações que, progressivamente, vão dominando. Dessa forma, são as situações que dão sentido aos conceitos, tornando-se o ponto de entrada para um dado Campo Conceitual. Contudo, um só conceito precisa de uma variedade de situações para se tornar significativo. Da mesma maneira, uma só situação precisa de vários conceitos para ser analisada. Quando se refere à ideia de história, o autor nos diz que o conhecimento dos alunos é formado a partir do contato do estudante com a situação, e isso ocorre progressivamente (VERGNAUD, 1990).

Esses são alguns dos motivos que levaram ao estudo de Campos Conceituais e não de situações isoladas ou conceitos isolados. Segundo Vergnaud (1994), outra razão para esse estudo vem do fato de os estudantes dominarem certas classes de situações mais simples antes de dominarem outras mais complexas. Podem-se passar vários anos para que um estudante 
domine uma situação simples e passe a dominar outra mais complexa. Durante esse processo, ele passa por:

[...] situações, palavras, algoritmos e esquemas, símbolos, diagramas e gráficos... e aprenderá, às vezes por descoberta, às vezes por repetição, às vezes representando e simbolizando, às vezes diferenciando, às vezes por redução de diferentes coisas para outras. Isso porque o panorama da aquisição do conhecimento é muito complexo [...] (VERGNAUD, 1994, p. 46, tradução nossa).

Observa-se que, dentro desse panorama de aquisição do conhecimento, estão envolvidas as relações, propriedades, registros e representações inerentes ao conceito a ser formado, sendo importante utilizar uma variedade de situações para que ocorra a sua aprendizagem, não deixando de observar que os conceitos envolvidos numa dada situação podem ser bem diversos.

No Quadro 1, a seguir, apresentamos duas situações do Campo Conceitual Aditivo e que precisam apenas de uma operação de adição para a sua solução, mas que envolve conceitos e complexidades distintas.

\begin{tabular}{|l|l|}
\hline Situação & Conceito Aditivo \\
\hline $\begin{array}{l}\text { 1) Luara tem, em sua lancheira, dois tipos de doce. Ela tem três pirulitos e três brigadeiros. } \\
\text { Quantos doces Luara tem, no total? }\end{array}$ & $\begin{array}{l}\text { Composição } \\
\text { quantidades }\end{array}$ \\
\hline $\begin{array}{l}\text { 2) Luara tinha doces em sua lancheira e, no intervalo, ela comeu três desses doces e ainda } \\
\text { ficaram três doces em sua lancheira. Quantos doces havia na lancheira de Luara antes do } \\
\text { intervalo? }\end{array}$ & $\begin{array}{l}\text { Transformação de } \\
\text { quantidades }\end{array}$ \\
\hline
\end{tabular}

Quadro 1 - Exemplo de situações do Campo Aditivo Fonte: Exemplos criados pelos autores

Para resolver as situações do Quadro 1, o estudante faz uma adição das quantidades apresentadas, ou seja, três mais três. Contudo, os conceitos e relações envolvidos em cada situação, são distintos. Na composição têm-se uma relação entre partes e um todo, na primeira situação, são dadas as quantidades de duas partes (quantidade de pirulito e a de brigadeiro e é solicitado o valor do todo). Na transformação, a relação envolve uma quantidade inicial, uma quantidade final e uma transformação, ou seja, na segunda situação é dada a transformação (quantidade de doces consumida no intervalo), quantidade final de doces (quantidade que ficou na lancheira após o intervalo) e se busca a quantidade inicial de doces. Segundo Santana (2012), os estudantes dos anos iniciais do ensino fundamental têm melhor desempenho nas situações do tipo composição do que nas de transformação. Esse resultado pode ser explicado, se observamos o nível de complexidade em cada tipo de situação.

Para melhor compreensão, explicitamos, abaixo, segundo Vergnaud (1996), o que vem a ser o Campo Conceitual das Estruturas Aditivas. 


\subsection{Campo Conceitual Aditivo}

De acordo com Vergnaud (1996), o Campo Conceitual das Estruturas Aditivas é, ao mesmo tempo, o conjunto das situações cujo tratamento implica uma ou várias operações de adição ou de subtração ou, ainda, a combinação das duas, além de congregar o conjunto de conceitos, propriedades, teoremas, relações e resultados que permitem fazer análises a respeito de situações que envolvem tais operações, como atividades matemáticas.

Santana (2012) aportou-se às definições e classificações apresentadas por Vergnaud (1982, 1996) e em Magina et al. (2001) para determinar as categorias de situações aditivas, conservando os raciocínios básicos definidos por Vergnaud, como se apresentam:

Composição: são situações nas quais se tem as partes e um todo. Exemplo: na gaveta tem seis balas de chocolate, três de hortelã e quatro de morango. Quantas balas tem na gaveta?

Transformação: são situações que têm um estado inicial, uma transformação e um estado final. Exemplo: Maria tinha $\mathrm{R} \$ 12,00$ e comprou uma boneca por $\mathrm{R} \$ 4,00$. Com quantos reais Maria ficou?

Comparação: são situações nas quais é estabelecida uma relação entre duas quantidades, uma denominada de referente e a outra de referido. Exemplo: Carlos tem cinco anos. Taís tem sete anos a mais que ele. Quantos anos tem Taís?

Composição de várias transformações: são situações nas quais são dadas transformações e se busca uma nova transformação a partir da composição das transformações dadas. Exemplo: José tem livros de histórias infantis. Ele ganhou cinco livros de seu pai e quatro livros de sua tia. José resolveu dar três dos seus livros mais velhos para seu amigo Jonas. Descontando os livros que José deu, em quanto aumentou a quantidade de livros de José?

Transformação de uma relação: são situações nas quais é dada uma relação estática e se busca uma nova, que é gerada a partir da transformação da relação estática dada. Exemplo: Saulo devia R \$ 8,00 a Glebson, pagou $\mathrm{R} \$ 5,00$. Quanto ele deve agora?

Composição de relações estáticas: duas ou mais relações estáticas se compõem para dar lugar a outra relação estática. Exemplo: Ana deve quatro figurinhas a Bete, três a Cris e seis a Mara. Quantas figurinhas Ana deve ao todo?

\section{Formação continuada e desenvolvimento profissional de professores}

São muitos os estudos em formação de professores que vêm sendo desenvolvidos no 
Brasil. Contudo, em decorrência da abrangência das problemáticas enfrentadas na formação inicial ou na continuada, seus efeitos pouco têm avançado e se refletido na educação básica, especificamente no interior das salas de aula das escolas públicas brasileiras. Nesse sentido, pretendemos, aqui, dialogar com a literatura sobre a formação continuada de professores, sobretudo a respeito do desenvolvimento profissional em práticas colaborativas.

A proposta para um trabalho colaborativo que coloque o diálogo entre a teoria, vista na academia, e a prática, posta na sala de aula, é um ponto de partida para se buscar caminhos em que a teoria possa auxiliar as práticas e os processos de ensino.

Nesse mesmo caminhar, Fiorentini e Miorin (2010, p. 23) expressam conceitualmente que "o trabalho [de um grupo] colaborativo é uma oportunidade para indivíduos aprenderem e crescerem juntos, pois, ao colaborar, o professor se abre a novas perspectivas e ideias do como, do por quê e do que ensinar". Assim, o conhecimento é compartilhado e o desenvolvimento profissional conquistado, de forma constante, através das interações que se materializam em conjunto, com professores da educação básica e pesquisadores, retroalimentando suas práticas pedagógicas, de forma cíclica, comprometida, ética e dialeticamente constituída (FREITAS, 1995; FIORENTINI; MIORIN, 2010).

Enfim, nesse envolvimento metodológico, a universidade se associa ao chão da escola, e esta, por sua vez, alimenta, com base nas suas práticas, a condução da formação de professores, num movimento dialético, constituído por relações complementares e, de preferência horizontalizadas, de formação e desenvolvimento profissional, em que os pesquisadores da universidade e os professores da educação básica dialogam em prol de um bem comum e unilateral, de modo que a "identidade profissional configure-se como uma identidade coletiva" (BRZEZINSKI, 2002, p. 8).

Por essa ótica, a formação de professores é constituída pelo ato de formar o sujeito, educar o profissional para o exercício das funções, inerentes ao magistério, assumindo, assim, uma posição de "inacabamento", que tem começo, mas não tem fim, vinculada à sua história de vida, em permanente processo de formação, que proporciona preparação profissional, porque "contínuo é o homem e não o curso" (FUSARI, 1984, p. 54).

Essas discussões se ocupam numa centralidade da formação do professor reflexivo, cujas bases podem ser encontradas em John Dewey (1859 - 1952), e essas ideias foram retomadas e se difundiram com Schön (1992) e Zeichner (1998, 2002), em prismas opostos, no entanto complementares, sugerindo um modelo de prática reflexiva, ou seja, reflexões do indivíduo sobre a experiência vivida.

Schön (1992) centra sua concepção de desenvolvimento de uma prática reflexiva no 
próprio professor, em três ideias emergentes, a saber: o conhecimento na ação, a reflexão na ação e a reflexão sobre a reflexão na ação. É o tradicional modelo descrito, na literatura educacional, pela indissociabilidade ação - reflexão - ação, com vistas à formulação de novas práticas, a partir do contato direto do professor com novas orientações conceituais, decorrentes de um processo formativo, de modo que esse professor analise, constantemente, o seu próprio fazer docente, ciente das bases teóricas que fundamentam suas práticas.

Já Zeichner (1998, 2002), apresenta uma crítica à relação dialógica que a atividade reflexiva exige e é tratada por Schön, como um processo solitário, quando o professor se mantém em comunicação apenas com sua situação e não com outros profissionais. Nesse cenário, o autor centra suas ideias sobre a prática reflexiva em três elementos principais, a saber: (a) primeiro, que as reflexões do professor não devem se centrar apenas em seu próprio exercício profissional, mas também nas condições nas quais é produzido tal exercício; (b) segundo, a prática reflexiva deverá levar em conta os problemas relacionados à questão da desigualdade e da injustiça em sala de aula, envolvendo valores éticos, estéticos e morais, pois, sem a valorização desses aspectos, o autor afirma que o ensino reflexivo fica limitado à racionalidade; e, por fim, (c) a ideia de que a prática reflexiva consiste no compromisso em favor da reflexão enquanto prática social, ou seja, torna-se necessário vincular a reflexão do professor à luta pela justiça social.

Sendo assim, torna-se importante que uma formação possibilite ao professor a incorporação à sua prática de contribuições dessas duas concepções: olhar para o seu próprio fazer docente (prática reflexiva em Schön), valorizando seu entorno social (prática reflexiva em Zeichner), pois os interesses defendidos pelos precursores da prática reflexiva para a formação de professores não são afetados pelas divergências que eles apresentam entre si, mas por suas relações complementares, já que o importante é a posição prático-reflexiva que se sustenta na formação do professor que ensina Matemática.

Nesse processo, o compartilhar é imprescindível, para que haja crescimento pessoal e coletivo. Consequentemente, essa proposta também encontra respaldo numa visão formativa definida por Nóvoa (1995), quando estabelece três dimensões importantes, no processo de formação dos profissionais da educação, a saber: (a) a dimensão pessoal, vinculada às condições de vida do professor; (b) a dimensão profissional, no que se refere à profissionalização desse agente da ação educativa; e (c) a dimensão institucional, no que se refere ao investimento realizado pelas instituições para obtenção de seus objetivos educacionais.

Desse modo, assumimos, como presuposto, que essa relação equilibrada trará 
contribuições ao desenvolvimento profissional dos envolvidos e, em relação às contribuições conceituais sobre o desenvolvimento profissional docente, tendo em vista, também, a diversidade de conceitos presentes na literatura, é sempre interessante sustentar a visão de um autor e, para tanto, as contribuições expressas por Cruz (2000) sintetizam o conceito de desenvolvimento profissional docente como a articulação equilibrada entre a dimensão científica e a pedagógica, no exercício da docência, em seus respectivos níveis, em se tratando da educação na realidade da escola pública brasileira, preferencialmente.

Nesse contexto, o desenvolvimento profissional docente pode ser considerado, conforme expressa o autor, a partir da "[...] evolução progressiva da função docente face aos modos e situações de maior profissionalismo que se caracterizam pela profundidade do juízo crítico e sua aplicação na análise global dos processos implicados nas situações de ensino para atuar de maneira inteligente" (CRUZ, 2000, p. 20).

Por fim, é na associação de formação com o desenvolvimento profissional que estaremos, efetivamente, contribuindo com os aspectos considerados para a melhoria da qualidade da educação básica, preferencialmente no contexto da escola pública brasileira.

\section{Caminho metodológico}

Para este estudo, estamos considerando um recorte da pesquisa intitulada Um estudo sobre o domínio das Estruturas Aditivas nas séries iniciais do Ensino Fundamental no Estado da Bahia, a qual denominamos Pesquisa das Estruturas Aditivas (PEA), realizada de 2009 a 2011. Tal pesquisa foi financiada pela Fundação de Amparo à Pesquisa do Estado da Bahia (FAPESB), e desenvolvida em uma rede colaborativa entre pesquisadores de universidades públicas do Estado da Bahia e de grupos de estudos de professores da educação básica que sediam Núcleos de Pesquisa da Sociedade Brasileira de Educação Matemática, Regional Bahia (SBEM/BA).

Em linhas gerais, a rede era formada por sete núcleos, e teve como finalidade principal desenvolver uma formação colaborativa com professores da educação básica e pesquisadores, visando à construção de propostas, com possibilidade de serem implementadas na sala de aula, que busquem minimizar dificuldades no ensino e na aprendizagem da adição e da subtração, nos anos iniciais do ensino fundamental, inspirada na TCC, especificamente as Estruturas Aditivas de Vergnaud (1982). 


\subsection{O caminhar com o PEA: abordagem, sujeitos e percurso metodológico}

Para o presente estudo, é assumida uma abordagem qualitativa, na perspectiva de pesquisa-ação que, conforme Fiorentini e Lorenzato (2006, p.112),

é um tipo especial de pesquisa participante, em que o pesquisador se introduz no
ambiente a ser estudado, não só para observá-lo e compreendê-lo, mas sobretudo
para mudá-lo em direções que permitam a melhoria das práticas [...]. Ou seja, é uma
modalidade de atuação e observação centrada na reflexão-ação.

No primeiro ano da pesquisa, em 2009, foi feito um diagnóstico, com o levantamento do desempenho de 5.807 estudantes do $2^{\circ}$ ao $5^{\circ}$ ano de 70 escolas, distribuídas em 47 municípios baianos. O teste, composto por 18 situações-problemas de adição e subtração, revelou baixos índices de acerto. Em média, houve 36,45\% de acerto. Tal resultado norteou o trabalho colaborativo, desenvolvido no ano de 2010, com 26 pesquisadores, uma diretora de escola, oito coordenadoras pedagógicas e 73 professores.

Para este estudo, consideramos os resultados do processo formativo do Núcleo Sede da Rede, que era responsável pela coordenação geral do projeto, situado num município da Região Sul do Estado da Bahia, que envolveu 18 professores, três pesquisadores e cinco escolas de sete municípios de regiões circunvizinhas ao Núcleo Sede.

A formação colaborativa foi desenvolvida com a realização de, no mínimo, um encontro mensal na sede de cada Núcleo de Pesquisa. Esses encontros tiveram como objetivos principais: reunir os professores e pesquisadores para fomentar discussões em relação à aprendizagem e ao ensino de conceitos do Campo Conceitual das Estruturas Aditivas; levantar as principais dificuldades encontradas no ensino do referido Campo Conceitual; desenvolver estratégias de ensino que contribuíssem para o ensino desse Campo Conceitual; e propiciar a troca de experiências entre os participantes do grupo colaborativo.

Tal formação ocorreu de forma espiralar, promovendo o ciclo de Reflexão inicial Planejamento em grupo - Planejamento em plenária - Reflexão em grupo - Reflexão em coletivo. Esse ciclo foi repetido sete vezes, durante o ano letivo, e complementado com um encontro de encerramento. Desse modo, foram trabalhadas, em cada encontro, uma categoria das situações-problemas aditivas intituladas: composição, transformação, comparação, composição de duas transformações, transformação de uma relação e composição de duas relações, segundo Vergnaud (1982, 1996), com a releitura, feita por Santana (2012), a saber: composição, transformação, composição de várias transformações, transformação de uma relação e composição de relações estáticas. 
A Reflexão Inicial ocorria a partir do resultado do instrumento diagnóstico, aplicado em 2009, em que era apresentado aos professores o resultado do desempenho dos estudantes na categoria de situações-problemas, com os dados das escolas em que eles atuavam, bem como o quadro comparativo desses resultados com as outras seis regiões da Bahia, envolvidas no projeto. Em seguida, os pesquisadores apresentavam os conceitos e a estrutura das situações da categoria de situações-problemas elencada para o encontro.

Depois de compreendidos os conceitos, os professores eram divididos em quatro grupos, conforme o ano escolar em que atuavam na sua escola. E, com a mediação dos pesquisadores, era realizado o que denominamos de Planejamento em Grupo, no qual os professores elaboravam estratégias de ensino para trabalhar com os estudantes. Em seguida, eles preenchiam um relatório de atividade planejada com as situações-problemas elaboradas, os conceitos matemáticos a serem abordados, o desenvolvimento da atividade e as expectativas de aprendizagem. Ao encerrar o Planejamento em Grupo, era feito o Planejamento em Plenária onde todos os grupos apresentavam, discutiam, davam sugestões, faziam mudanças e finalizavam, no coletivo, a estratégia a ser aplicada em cada ano escolar.

No encontro seguinte, a Reflexão em Grupo se dava a partir dos resultados advindos das aplicações feitas pelos professores, com o objetivo de o professor refletir sobre os resultados da aplicação da estratégia planejada, anteriormente, sendo preenchido um relatório da atividade desenvolvida, no qual era relatada a quantidade de estudantes envolvidos na aplicação, se houve ou não mudanças no que foi planejado e no que foi aplicado, o desempenho e esquemas de resolução dos estudantes e a avaliação da estratégia de ensino.

Na sequência, era feita a Reflexão em Coletivo, na qual cada grupo apresentava para a plenária os resultados de sua aplicação e, além disso, fazia-se uma reflexão coletiva sobre o que poderia ser mantido ou alterado para próximos planejamentos e ações. Depois de ampla reflexão sobre os resultados apresentados pelos grupos, os pesquisadores promoviam novamente uma Reflexão Inicial, com os resultados da categoria de situações-problemas elencada para aquele encontro, seguida das demais fases do ciclo listadas anteriormente.

No período de oito meses, foram realizados sete encontros com essa dinâmica. O oitavo encontro objetivou refletir e avaliar todo o processo formativo. Para isso, os professores preencheram um relatório final, composto de duas partes: uma composta de dez questões sobre o perfil profissional atual e, outra, de sete questões objetivando que fossem feitas reflexões a respeito do processo formativo realizado. 
A análise qualitativa deste estudo foi feita tomando como base as sete questões reflexivas do relatório final e será discutida, no eixo a seguir, a partir da perspectiva de análise do conteúdo, definida como:

\begin{abstract}
[...] um conjunto de técnicas de análise das comunicações que utiliza procedimentos sistemáticos e objetivos de descrição do conteúdo das mensagens [...]. A intenção da análise de conteúdo é a inferência de conhecimentos relativos às condições de produção e de recepção das mensagens, inferência esta que recorre a indicadores (quantitativos ou não) (BARDIN, 2006, p. 38).
\end{abstract}

É, portanto, nas palavras do autor, com base na explicitação do conteúdo manifesto que se inicia o processo de análise, com vistas a refletirmos sobre o objetivo da pesquisa aqui delineada e tendo como apoio os indícios manifestos no âmbito das comunicações estabelecidas entre pesquisadores e interlocutores. Assim, acreditamos obter informações necessárias para analisar sobre as possíveis reflexões dos professores relativas à aplicação da Teoria dos Campos Conceituais durante o processo de formação, bem como a importância do trabalho colaborativo na formação continuada do professor que ensina Matemática.

\title{
5 Aplicações da Teoria dos Campos Conceituais: o trabalho colaborativo na formação continuada e o processo de ensino
}

Para relatarmos as reflexões originárias na ação formativa, trazemos o olhar de quatro professoras, agentes do PEA e participantes da ação formativa, selecionadas a partir dos critérios assim definidos: a) possuírem formação inicial em Pedagogia, por se tratar de um estudo sobre formação continuada do professor que ensina Matemática; b) situação funcional: professoras efetivas das escolas pesquisadas, três com mais de 20 anos de serviço e uma com três anos de serviço, apenas tentando enfocar a relação entre professoras experientes e uma jovem professora; e, c) o campo de atuação no exercício dos anos iniciais do ensino fundamental da educação básica brasileira.

Por questões éticas da pesquisa, os nomes que aparecem neste texto são fictícios, no sentido de preservarmos as identidades das participantes.

A professora Andréia tinha 53 anos de idade, graduada em Pedagogia, concluída no ano de 2006, lecionava há 28 anos e, há dois anos, trabalhava na escola, objeto deste estudo, nos turnos matutino e vespertino, totalizando um regime de trabalho de 40 horas semanais.

A professora Marli tinha 43 anos de idade, graduada em Pedagogia e pós-graduação lato sensu, nível de especialização, em Psicopedagogia Institucional, lecionava há 25 anos e, há dois anos, trabalhava na escola em que foi desenvolvida a formação continuada com o 
PEA, nos turnos matutino e vespertino, totalizando um regime de trabalho de 40 horas semanais.

A professora Sueli tinha 26 anos de idade, graduada em Pedagogia e pós-graduação lato sensu, nível de especialização, em Coordenação Pedagógica, lecionava há três anos e, há dois anos, trabalhava na escola em que foi desenvolvida a pesquisa, no turno vespertino, totalizando um regime de trabalho de 20 horas semanais.

E, por fim, a professora Verônica tinha 38 anos de idade, graduada em Pedagogia, lecionava há 21 anos e, há 20 anos, trabalhava na escola em que foi desenvolvida esta pesquisa, nos turnos matutino e vespertino, totalizando uma carga horária de 40 horas semanais.

Buscando resposta à questão da pesquisa, ou seja, compreender quais as reflexões dos professores a respeito da aplicação da Teoria dos Campos Conceituais, durante um processo de formação continuada que abordou o trabalho com conceitos das Estruturas Aditivas nos anos iniciais, trazemos, aqui, algumas perguntas reflexivas, apresentadas no relatório final, que nos deram subsídio para avaliação da realização do projeto sobre o qual enfatizamos as discussões acerca das Estruturas Aditivas, conforme situadas anteriormente.

Com base nas categorias de Vergnaud $(1982,1996)$, foi perguntado às professoras se a organização dos encontros, seguindo o nível de complexidade das extensões e das categorias das Estruturas Aditivas, facilitou o entendimento teórico durante a formação. Vejamos o que pode-se verificar em suas respostas:

Sim, porque nos deu um suporte em relação às atividades matemáticas a serem aplicadas com os alunos e pudemos avaliar processualmente o aprendizado dos mesmos dentro de cada operação trabalhada (PROFESSORA MARLI, 2010).

A resposta da professora Marli explicita que a formação realizada perpassa pelo processo de planejamento, aplicação das atividades matemáticas na sala de aula, bem como no processo avaliativo. É possível observar a influência da organização dos níveis de complexidade que a teoria apresenta para as Estruturas Aditivas, na ação pedagógica da sala de aula, que acompanha desde o planejamento até a efetivação do ensino dessas atividades

[...] deu um suporte em relação às atividades matemáticas a serem aplicadas (PROFESSORA MARLI, 2010).

Esse ideário formativo ganha ressonância, também, a partir das palavras da professoras Andréia e Sueli, que destacam as contribuições desse processo de formação no ensino e, consequentemente, na aprendizagem dos estudantes envolvidos, pois tal construção:

[...] facilitou muito, [porque] antes fazia as atividades sem entender o mecanismo e a dinâmica contida (PROFESSORA ANDRÉIA, 2010). 
Essa organização contribuiu ricamente com a forma de transmitir os conteúdos para que os alunos tivessem [um] bom rendimento (PROFESSORA SUELI, 2010).

Desse modo, todas foram unânimes em afirmar positivamente, além de perceberem a importância de se trabalhar nessa perspectiva teórico-metodológica, vendo nela uma possibilidade de um suporte para realizar o planejamento das aulas, focando a formação e o domínio do conceito pelo estudante, a sua própria compreensão da organização desses conceitos e sua influência direta no processo de ensino, alcançando a aprendizagem do estudante, possibilitando uma maior segurança e efetividade em sua prática docente.

A fala da professora Verônica traz mais inovações a essa questão, destacando uma mudança de postura, como ela mesma descreve no trecho a seguir:

Sim, porque apesar de aplicar situações-problema nos anos anteriores, [eu] não tinha conhecimentos dessas categorias e sua aplicação [na minha prática] era de forma inadequada, com o uso daquelas velhas perguntas (é de mais? ou é de menos?). [Percebia que isso] não facilitava o aprendizado do aluno, pois ele não era provocado a interpretar os mesmos (PROFESSORA VERÔNICA, 2010).

Sua reflexão demonstra a mudança de postura em relação à atividade docente, decorrente do trabalho com os níveis de complexidade inerentes à própria teoria. Fica evidente em sua fala que, mesmo trabalhando com as situações-problemas, nos anos anteriores à realização dessa formação, o olhar sobre o conhecimento matemático era outro. A formação proporcionou uma visão sobre o conhecimento teórico e a possibilidade de interlocução desse conhecimento, com sua prática docente. Professora Verônica exemplifica, em sua fala, que a interlocução com a teoria pôde contribuir para que ela refletisse sobre a necessidade de os estudantes interpretarem as situações e, dessa forma, facilitar o seu aprendizado.

Para além das respostas dadas pelas professoras, é possível relatar o comportamento e as reflexões feitas ao longo da formação. Todos os participantes relatavam a dificuldade e os benefícios na mudança de postura, no momento de trabalhar com o estudante, conduzindo-o à interpretação e não mais à busca pelas palavras-dicas que caracterizariam a operação a ser realizada.

Além do mais, o relato das professoras permitiu-nos depreender que as estratégias teóricas para a formação (nesse caso, as Estruturas Aditivas) escolhidas favoreceram a produção de saberes docentes, proporcionando avanços no conhecimento das professoras, tanto de natureza específica quanto metodológica.

Em relação ao fato de a formação ser pautada na metodologia da pesquisa colaborativa, valorizando a participação de todos, com a criação das estratégias de ensino, das 
situações-problemas e a socialização dos resultados da aplicação, perguntamos às nossas professoras se essa metodologia foi satisfatória para elas, o que nos foi respondido, conforme destacamos a seguir:

Sim, principalmente no que diz respeito à socialização dos resultados, onde todos [os envolvidos] compartilharam suas experiências em sala de aula, [nos ajudando] a construir as situações de uma forma mais contextualizada, provocando o exercício da leitura e a interpretação dos dados apresentados (PROFESSORA MARLI, 2010).

Essas colocações da professora Marli manifestam satisfação com a metodologia desenvolvida, e um ponto forte que merece ser destacado na sua fala é a socialização dos resultados com a troca de experiências, em prol da elaboração de situações-problemas, buscando a contextualização. Esse processo, pautado nos preceitos da Teoria dos Campos Conceituais, fortalece a autonomia do professor, dando-lhe mais segurança para o planejamento das suas atividades de sala de aula, o que se reverbera na fala da professora Andréia.

Ao elaborar as situações-problemas com os conhecimentos que adquiri no PEA, me sinto mais segura, sendo que essa atividade discutida e elaborada na sala, com a participação do grupo, tornou-se mais especial e entendida por todos (PROFESSORA ANDRÉIA, 2010).

Essa afirmativa indica que, além das influências positivas da formação colaborativa, fica evidenciada a influência que os conhecimentos teóricos exerceram sobre a segurança que Andréia passa a ter, ao elaborar situações-problemas aditivas. Essa postura evidencia o protagonismo do processo de (auto)formação e um repensar da prática que, muitas vezes, estava enraizada no trabalho docente, centralizada unicamente no livro didático, o que pode ser exemplificado a partir das palavras da professora Verônica.

Sim, a partir desse processo, pude perceber a importância do próprio professor pautar seu planejamento em situações-problema, voltado para a realidade [de sua] classe e não ficar [restrito apenas ao] livro didático, [mas] sim criar situações que lhe apresente, através de pesquisa, como nesse projeto, uma nova forma de pensar e agir [em sala de aula] (PROFESSORA VERÔNICA, 2010).

É importante ressaltar o reconhecimento dado a situações-problemas pela professora Verônica, quando ela destaca que uma situação-problema deve começar onde os estudantes estão. De fato, uma atividade matemática deve levar em consideração a compreensão atual dos estudantes e que lhes faça sentido (VAN DE WALLE, 2009).

Essa ação demarca a essência do que buscamos no seio da atividade formativa, como preconiza Schön (1992): uma reflexão do professor, agente do processo, rumo à modificação de sua prática, que não se realiza a partir de uma forma mecanizada e automática, mas situada com base no fundamento téorico-prático, desenvolvido durante seu processo formativo. 
Por fim, foi pedido às professoras que relatassem as contribuições que a formação do PEA trouxe para sua prática pedagógica, no que se refere ao significado pessoal, sentimentos, dificuldades e aprendizagens realizadas. Nesse sentido, a professora Andréia abre tais reflexões, situando que a formação realizada lhe trouxe condições de sanar as dificuldades vivenciadas no ensino de Matemática, conforme destacado a seguir:

Hoje me sinto mais segura em relação à situação-problema, pois, quando a levo para meu aluno, já refleti e sanei minhas dificuldades (PROFESSORA ANDREIA, 2010).

Nesse mesmo caminhar, a professora Marli sinaliza novos sentimentos em relação à Matemática, desvelando as possibilidades de um trabalho em sala de aula mais acessível e dinâmico às aprendizagens dos estudantes, com vistas a promover outras concepções sobre o ensino da Matemática:

Nos despertou para o ensino de uma matemática mais prática, acessível e dinâmica, fazendo com que a turma [os seus alunos] deixasse de ver a disciplina de uma forma negativa (PROFESSORA MARLI, 2010).

Tal reflexão possibilita-nos compreender que nascem novos olhares e sentimentos para com a Matemática, o que passa a se refletir em outros aprendizados profissionais, assim como perceber a sensibilidade para se trabalhar as dificuldades dos estudantes, o que se complementa com as palavras da professora Sueli, que sinaliza a necessidade de valorização das questões teóricas debatidas durante a formação, com vistas a trazer outros significados ao ensino das Estruturas Aditivas: “A formação contribuiu para refletir sobre a necessidade que têm os alunos de interpretar [problemas]" (PROFESSORA SUELI, 2010).

A colocação da professora Sueli revela nova postura e abertura para as possibilidades de refletir sobre as necessidades de aprendizagem do estudante. Isto corrobora com as afirmações feitas por Vergnaud (1996) a respeito das competências dos estudantes na resolução de situações-problemas, que surgem na escolha certa dos dados e das operações e, no nosso entender, isso só é possível com a interpretação da situação-problema dada.

Essas afirmativas ilustram que o processo formativo parece conduzir o professor a novas posturas diante da sua ação pedagógica, no que diz respeito ao trabalho com situaçõesproblemas aditivas. No mesmo caminho, encontram-se as palavras trazidas pela professora Verônica, que enfatizam as reflexões decorrentes da formação realizada, destacando suas contribuições à sua prática pedagógica na educação básica:

De continuar buscando inovações positivas que venham facilitar a aplicação da matemática para o aprendizado e a compreensão do aluno, levando-o a buscar e descobrir suas próprias respostas, novas experiências e aplicar a matemática no seu cotidiano (PROFESSORA VERÔNICA, 2010). 
É possível perceber diferentes contribuições elencadas pelas professoras. Elas perpassam desde sentimentos até novas aprendizagens e, percebe-se nas suas falas, uma mudança de atitude: a preocupação em mudar sua prática com vistas à aprendizagem dos estudantes. E a formação lhes proporcionou essa mudança: o refletir sobre o seu ensino, contribuindo para o seu crescimento e desenvolvimento profissional.

Concernindo ao que afirma Ibiapina (2008), referindo-nos à formação colaborativa desenvolvida no PEA, numa perspectiva emancipatória que objetiva colocar o professor no centro da investigação, colocando-o como sujeito ativo, como agente da história educativa e, oportunizando a dialética entre a teoria e a prática, torna-se possível analisar as aplicações e contribuições da Teoria dos Campos Conceituais para o processo de ensino desvelado em sala de aula, durante um processo de formação continuada. As aplicações caminham desde o planejamento de ações pedagógicas, às suas aplicações na sala de aula, até privilegiar um processo avaliativo processual da aprendizagem do estudante, no que diz respeito às Estruturas Aditivas.

\section{Considerações finais}

A análise deste estudo nos permitiu uma visão da Teoria dos Campos Conceituais e sua aplicação na formação do professor. Vivenciamos uma oportunidade de evidenciar a dialética entre a teoria e a prática, possibilitando analisar, por meio da aplicação da teoria, pontos como: o planejamento de ações pedagógicas, a prática de ensino desvelada em sala de aula, bem como processos avaliativos da aprendizagem do estudante.

Esses resultados nos revelam caminhos para possíveis soluções das dificuldades de aprendizagem dos estudantes, entre eles: inserções de formadores de professores, tanto na formação inicial como na continuada, instigando-os a reflexões que, segundo Schön (1992), os conduzam a modificar sua própria prática e que essa prática seja parte integrante do processo formativo reflexivo, na realidade social do indivíduo (ZEICHNER 1998, 2002).

No entrelaçamento entre a teoria e a prática, o professor traz à baila a importância da condução teórica para formas de desenvolver o processo de ensino, de modo a desencadear a aprendizagem do estudante. A teoria pode proporcionar a compreensão das relações envolvidas num dado conceito matemático e essa compreensão pode evidenciar: mudanças na prática do professor, mais segurança conceitual e, consequentemente, melhores práticas de ensino. 
Por fim, deixamos aqui nossas ideias sobre a Teoria dos Campos Conceituais num processo de formação continuada para outras reflexões, no sentido de se pensar a prática da sala de aula embasada em teorias que facilitem a mediação do professor.

\section{Referências}

BARDIN, L. Análise de conteúdo. Trad. L. de A. Rego e A. Pinheiro. Lisboa: Edições 70, 2006.

BRZEZINSKI, Iria. Profissão Professor: identidade e profissionalização docente. Brasília: Plano, 2002.

CRUZ, M. F. Desarollo Profesional Docente. Granada: Grupo Editorial Universitário, 2000.

FIORENTINI, D.; MIORIN, M. Â. Pesquisar \& escrever também é preciso: a trajetória de um grupo de professores de matemática. In: FIORENTINI, D.; MIORIN, M. Â. (Org.). Por trás da porta, que matemática acontece? Campinas: Ílion, 2010. p. 17-48.

FIORENTINI, D.; LORENZATO, S. Investigação em Educação Matemática: percursos teóricos e metodológicos. São Paulo: Autores Associados, 2006.

FREITAS, L. C. de. Crítica da Organização do Trabalho Pedagógico e da Didática. 9. ed. Campinas: Papirus, 1995.

FUSARI, J. C. O Planejamento Educacional e a Prática de Educadores. Revista Ande, São Paulo, n. 8, p. 32-36, 1984.

IBIAPINA, I. M. L. de M. Pesquisa colaborativa: investigação, formação e produção de conhecimentos. Brasília: Líber Livro Editora, 2008.

MAGINA, S. et al. Repensando adição e subtração: contribuições da teoria dos campos conceituais. 2. ed. São Paulo: PROEM, 2001.

NÓVOA, Antônio (Org.). Vidas de Professores. 2. ed. Lisboa: Porto Editora, 1995.

SANTANA, E. R. dos S. Adição e Subtração: o suporte didático influencia a aprendizagem do estudante? Ilhéus: Editus, 2012.

SCHÖN, D. Formar professores como profissionais reflexivos. In: NÓVOA, Antônio (Coord.). Os professores e a sua formação. Lisboa: Dom Quixote, 1992. p.79-91.

VAN DE WALLE, J. A. Matemática no ensino fundamental: formação de professores e aplicação em sala de aula. Tradução de Paulo Henrique Colonesse. 6 ed. Porto Alegre: Artmed, 2009.

VERGNAUD, G. A Classification of Cognitive Tasks and Operations of Thought Involved in Addition and Subtraction Problems. In. T. Carpenter; T. Romberg; J. Moser (Eds.). Addition and Subtraction: a cognitive Perspective. New Jerssey: Lawrense Erlbaun, 1982. p. 39-59.

VERGNAUD, G. Multiplicative structures. In. HIEBERT, H. and BEHR, M. (Ed.). Research Agenda in Mathematics Education. Number Concepts and Operations in the Middle Grades. Hillsdale, N.J.: Lawrence Erlbaum, 1988. p. 141-161.

VERGNAUD, G. La théorie des champs conceptuels. Recherches en Didactique des Mathématiques, Grenoble, v. 10, n. 23, p. 133-170, 1990. 
VERGNAUD, G. Multiplicative conceptual field: what and why? In. Guershon, H. e Confrey, J. (Eds.). The development of multiplicative reasoning in the learning of mathematics. Albany: State University of New York Press, 1994. p. 41-59.

VERGNAUD, G. A Teoria dos Campos conceituais. In: BRUN, J. Didáctica das matemáticas. Tradução de Maria José Figueiredo. Lisboa: Instituto Piaget,1996. p. 155-191.

ZEICHNER, K. M. Para além da divisão entre professor-pesquisador e pesquisador acadêmico. In: GERALDI, C. M. G.; FIORENTINI, D.; PEREIRA, E. M. de A. (Org.). Cartografia do Trabalho Docente: professor(a) - pesquisador(a). Campinas: Mercado das Letras, Coleção Leituras do Brasil, 1998. p. $207-236$.

ZEICHNER, K. M. Formando professores reflexivos para uma educação centrada no aprendiz: possibilidades e contradições. In: ESTEBAN, M. T.; ZACCUR, E. (Org.). Professora Pesquisadora: uma práxis em construção. 2. ed. Rio de Janeiro: DP\&A, 2002. p. 25 - 52.

Submetido em Abril de 2015. Aprovado em Agosto de 2015. 